\title{
PLC control system study of coaxial self-vibration and variable-frequency centrifuge of tube\&mould for new type well pipe
}

\author{
Jiangtao Liu, Jinggang Yi, Shanshan Li, Yazhou Xing, Haiyong Jiang
}

Mechanical \& Electronic Engineering College, Agricultural university of Hebei, Baoding 071001

email: liujiangtao2003@126.com

Keywords: well pipe; centrifuge; PLC; rotating speed

\begin{abstract}
To the problem of the unchanged rotating speed of the old well pipe centrifuge, the paper firstly introduces the composing and characteristic of coaxial self-vibration and variable-frequency centrifuge of tube\&mould for new type well pipe and educes the corresponding speed and time of the centrifugal molding for three stages. The control system is designed based on PLC. The actual production shows: the centrifuge has the high production efficiency and the eccentricity of well pipe produced by the centrifuge satisfies the well pipe industry standard.
\end{abstract}

\section{Introduction}

At present, the prestressed reinforced concrete well pipe (new type well pipe) is produced by mainly using ground (running wheel) type centrifuge and lathe type centrifuge. The rotating speed can not be changed. The centrifugal molding of new type well pipe utilizes the tube\&mould inside of the high-speed rotation to drive the concrete ingredients move in order to distribute and tense the concrete ingredients along the inner wall of tube\&mould and squeeze out the excess water to make well pipe with high density and high strength under the action of centrifugal force, gravity, vibration force, adhesion force and friction force. In the process of centrifugal molding, the speed is required to realize the conversion of the slow, medium and fast, and the self-vibration frequency is variable ${ }^{[1]}$ [2][3][4][5][6][7]

\section{Coaxial self-vibration and variable-frequency centrifuge of tube\&mould}

Coaxial self-vibration and variable-frequency centrifuge of tube\&mould for new type well pipe is composed of variable-frequency control system, hydraulic system, pressure device, pressure locking head, self-vibration wheel, tube\&mould, hydraulic supporting and protection device, transmission locking head, transmission device and motor etc. Coaxial self-vibration and variable-frequency centrifuge of tube\&mould for new type well pipe sees Figure 1 . The centrifuge finishes the whole process of start-up, acceleration, well pipe centrifugal molding, braking and parking with a start button. And the molding cycle is short and the efficiency is high.

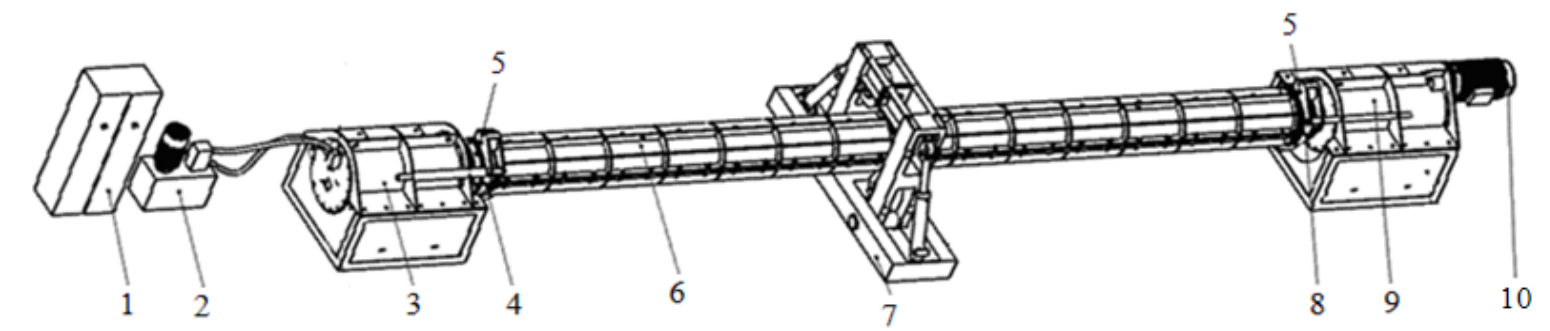

1.variable-frequency control system 2.hydraulic system 3.pressure device 4.pressure locking head 5.self-vibration wheel 6.tube\&mould 7.hydraulic supporting and protection device 8.transmission locking head 9. transmission device 10. motor

Fig.1. Coaxial self-vibration and variable-frequency centrifuge of tube\&mould

To solve the eccentric problem of the well pipe production, transmission device, pressure device and tube\&mould is coaxial in the long distance. Tube\&mould is supported by the hydraulic supporting and protection device in the middle position. Coaxial self-vibration and 
variable-frequency centrifuge of tube\&mould can produce well pipe from 1 to $18 \mathrm{~m}$. Well pipe of the different models/specifications accords with the standard of concrete and reinforced concrete well pipe industry standards. The actual measured pass rate is more than $99.8 \%$ and the well depth can reach $600 \mathrm{~m}$. The self-vibration wheel is symmetrically set up on the pressure locking head and transmission locking head. The small vibration is put on the pressure locking head and transmission locking head and the small vibration and the variable-frequency speed regulation of electronic control are combined to improve the molding speed, density and uniformity of the prestressed reinforced concrete well pipe. The productivity is increased by 2 times comparison with old type centrifuge and the density is high. Both ends of tube\&mould is provided with the independent elastic clamping device, which is convenient to replace and has the good sealing effect, to solve the problem of the slurry and avoid the slurry forming the waste residue, improve the environment of the well pipe production, save the energy and protect the environment. When tube\&mould rotates, tube\&mould above $8 \mathrm{~m}$ is supported by the hydraulic supporting and protection device in order to prevent the well pipe from jumping up and down and damaging the centrifuge, avoid the well pipe eccentricity(the well pipe wall thickness is not uniform) and increased the life span of centrifuge and tube\&mould.

\section{PLC control system}

\section{Rotating speed of centrifugal molding}

Rotating speed of uniform feeding. The centrifugal process parameters include centrifugal molding speed and centrifugal time. The centrifugal molding process includes uniform feeding, acceleration, density and dehydration. The corresponding centrifugal molding speed respectively match with slow, medium, and fast. In uniform feeding stage the rotating speed of tube\&mould must make the concrete ingredients generate the certain centrifugal force that is sufficient to overcome the gravity of the concrete ingredients in order to ensure the concrete ingredients to contact with the inner wall of well pipe and don't fall. At the same time, the rotating speed can not be too large to avoid the concrete layer. Given coaxial self-vibration and variable-frequency centrifuge of tube\&mould for new type well pipe and the self-vibration of the self-vibration wheel in the working process, the safety factor takes 1.25 to 1.5. The uniform feeding speed is as follows:

$$
n_{f}=(1.25 \sim 1.5) \frac{300}{\sqrt{r}}=\frac{375}{\sqrt{r}} \sim \frac{450}{\sqrt{r}}
$$

Density rotating speed. In the density stage, the rotating speed of tube\&mould must generate the enough centrifugal force in order to squeeze out the excess water in the concrete ingredients and overcome the gravity, adhesion force and friction force. The density rotating speed is as follows:

$$
n_{d}=52 \sqrt{\frac{P R}{\rho\left(R^{2}-r^{2}\right)}}(r / \mathrm{min})
$$

In the type: $P$ is the surface pressure of tube\&mould during the density molding; $R$ is the outside diameter of tube\&mould; $\rho$ is the concrete ingredients density.

\section{Working Process of centrifugal molding}

In the process of new type well pipe centrifugal molding, the high-speed rotating transmission device drives both ends of the elastic sealing tube\&mould to generate the centrifugal force in order to ensure the concrete ingredients to contact with the inner wall of well pipe under the action of centrifugal force and uniformly feed. Well pipe is preliminarily molded. As the rotating speed continues to rise, the centrifugal force makes a variety of particles of the concrete ingredients squeeze into the inner wall of tube\&mould and well pipe is uniformly and densely molded. The vibration of the self-vibration wheel is from 6 to 3 times for each rotation of tube\&mould in order to improve the molding speed and density. The centrifugal molding process is divided into 3 steps.

The first step: slow stage (uniform feeding stage). The rotating speed is from 80 to $120 \mathrm{r} / \mathrm{min}$. The corresponding time is from 0.5 to $1 \mathrm{~min}$.

The second step: intermediate stage (transitional stage). The corresponding time from 1 to 2 min. 
The transitional stage is the gradually increasing stage of tube\&mould from low speed to high speed and can effectively prevent the concrete ingredients from being damaged in the centrifugal process of new type well pipe. At the same time, the transitional stage also plays the feeding role.

The third step: high speed stage (dense molding stage). The rotating speed is from 400 to 560 $\mathrm{r} / \mathrm{min}$. The corresponding time is from 4 to $5 \mathrm{~min}$. The centrifugal force makes a variety of particles of the concrete ingredients squeeze into the inner wall of tube\&mould to squeeze out the excess water.

The rotatingspeed and the corresponding time of each stage are different with the specifications/models of well pipe. When the prestressed reinforced concrete well pipe (new type well pipe) is produced, the rotating speed of the large diameter is low speed and the rotating speed of the small diameter is high.

\section{PLC control system}

The control system includes PLC, frequency converter, hydraulic station, hydraulic cylinder and motor etc. the model of PLC is DVP40-ES200R, has $40 \mathrm{I} / \mathrm{O}$ and is the relay output type. The program capacity is $16 \mathrm{~K}$. The basic instruction execution speed is $0.54 \mu$ s. The model of frequency converter is SAJ8000. The parameters are as follows: three phase $380 \mathrm{~V}$, power $23 \mathrm{KW}$, frequency range from 0.5 to $650 \mathrm{~Hz}$ and low frequency torque output 180\%. PLC has the function of acceleration, deceleration and rotating stall prevention etc. the response time of high speed stop is fast. The operating characteristic of low frequency is good. PLC can control the high speed motor and also set up the frequency range and time in the input panel to control the rotating speed of centrifugal molding and density. The control system adopts the combined control mode of PLC and frequency converter. The frequency range of frequency converter is from 0 to $80 \mathrm{~Hz}$. Motor adopts four stage three phases AC. Reducer ratio is 4:1.The rising time of frequency converter is from 1 to 2 min. The maximum speed of tube\&mould is 550 $/ \mathrm{min}$. Given the uniform feeding, when the rotating speed reaches $100 \mathrm{r} / \mathrm{min}$, the frequency remains unchanged to delay from 10 to $20 \mathrm{~s}$ and evenly rises. The centrifugal molding is from 4 to $5 \mathrm{~min}$. The principle structure of PLC control system sees Figure 2.

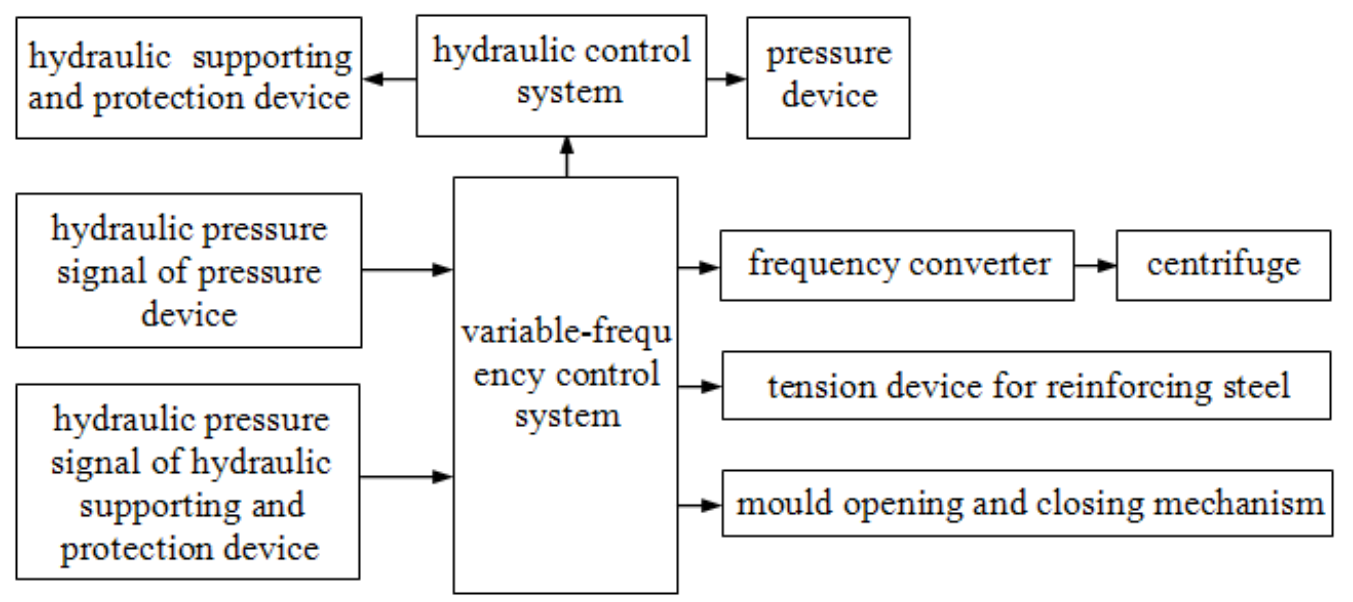

Fig.2. The principle structure of PLC control system

When working, the crane transports tube\&mould of filler to both ends of the centrifuge and both ends of tube\&mould docks with transmission locking head and pressure locking head. And then the automatic program button is start. The hydraulic system controls pressure device to extend in order to seal the elastic clamp. The pressure value of the hydraulic system reaches the setting point and the hydraulic system stops working. The pressure value is automatically controlled between $7 \mathrm{MPa}$ and 10MPa. The hydraulic supporting and protection device holds tube\&mould. At the same time, the pressure value is automatically controlled between $7 \mathrm{MPa}$ and $10 \mathrm{MPa}$. Start motor. And then transmission device drives pressure device and tube\&mould rotate at high speed to produce the centrifugal force in order to complete the centrifugal and dense molding. The hydraulic control system controls the hydraulic cylinder of pressure device and hydraulic supporting and protection device to retract. The crane transports tube\&mould to steam curing pond. 


\section{Centrifugal molding effect}

The eccentricity of the prestressed reinforced concrete well pipe produced by the coaxial self-vibration and variable-frequency centrifuge of tube\&mould for new type well pipe accords with the pumped well pipe industry standards. And well pipe has the characteristic of segregation, and high density, high strength and good smoothness. The appearance quality of well pipe is superior to the similar product. The actual centrifugal molding effect sees Figure 3.

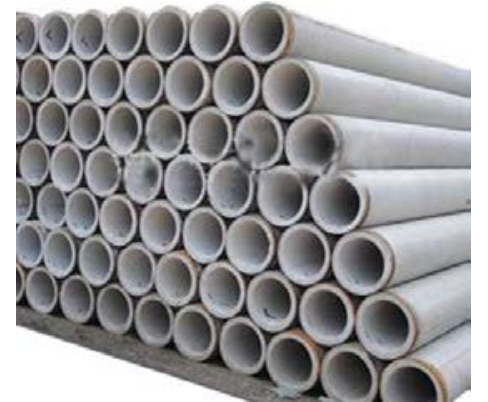

Fig.3. Actual centrifugal molding effect

\section{Conclusion}

Both ends of tube\&mould dock with the transmission locking head and pressure locking head of coaxial self-vibration and variable-frequency centrifuge of tube\&mould for new type well pipe. And transmission locking head and pressure locking head are coaxial with tube\&mould in the long distance. The self-vibration of self-vibration wheel and the variable-frequency speed regulation of electronic control are combined to improve the molding speed, density and uniformity of the prestressed reinforced concrete well pipe.

\section{Acknowledgement}

In this paper, the research was sponsored by Science and Technology Research Project of 2016 Colleges and Universities of Hebei Province (Project No. ZC2016159)

\section{References}

[1] FAN Jin-ling. Control system design of the plenum antic manipulator based on PLC [J]. Hydraulic and Pneumatic, 2010, (7): 36-37.

[2] Ceng Keping. Technical measures to ensure the quality of well pipe construction [J]. WEST-CHINA EXPLORATION ENGINEERING, 2005, (110): 45-46.

[3] LI Fenglan, LI Xiaoke, ZHAO Shunbo, GAO Rundong. Design Method for Centrifugal Shaping Steel Fiber Reinforced Concrete Pole [J]. JOURNALOF BASIC SCIENCE AND ENGINEERING, 2007, 15(2): 190-191.

[4] Zhang Yunguo, Zhao Shunbo, Zhang Tianguang. Study on distribution rule of steel fiber in spun-cast concrete[ J]. Journal of Materials Science and Engineering, 2004, (4): 602-603.

[5] Zhang Yunguo, Li Fenglan, Gao Rundong. Study on properties of steel fiber reinforced concrete by centrifugal method[J].China Concrete and Cement Products, 2005, (2): 38-40.

[6] CAO Dongmei. Development of the micro PLC system[J]. Machine Design and Manufacturing Engineering, 2015, 44(5): 65-67.

[7] YUAN Qing-ke, ZHAO Chong, LIN Li-ren. Design and Development of Control System for Pneumatic Manipulator Based on PLC[J]. Instrument Technique and Sensor, 2015, (11): 59-61. 